\title{
A "força theorica do methodo intuitivo": proposições de Justiniano de Mello e Silva para a educação das crianças no século XIX
}

\author{
Bárbara da Silva Santos* \\ Cristiano de Jesus Ferronato* \\ Anderson Santos ${ }^{* * *}$
}

\begin{abstract}
Resumo
No cerne dessas discussões e posterior à forte defesa da validação do método intuitivo, Justiniano de Mello, político, jornalista e professor, não poderia deixar de apresentar o seu posicionamento quanto às configurações da educação do seu tempo. Logo, delineamos, neste estudo, os princípios do método intuitivo elencados por este intelectual, os quais foram publicados em seus textos no jornal Sete de Março entre anos 1888 e 1891.

Palavras-chave: Justiniano de Mello e Silva; Método Intuitivo; Sentidos e educação; Século XIX.
\end{abstract}

\section{The "theoretical force of the intuitive method": propositions of Justinian Mello and Silva for the education of children in the century XIX}

\begin{abstract}
At the core of discussions and after the strong defense of the validation of the intuitive method, Justiniano de Mello, a politician, journalist and teacher, could not fail to present from his positioning the configurations of the education of his time. Therefore, we outline, in this study, the principles of the intuitive method listed by this intellectual which were published in his texts in the newspaper Sete de Março between years 1888 and 1891.

Palavras-chave: Justiniano de Mello e Silva; Intuitive Method; Senses and education; Century XIX.
\end{abstract}

\section{Introdução}

Frente a renovações pedagógicas que ocorreram na segunda metade do século XIX, o método intuitivo foi visto como o solucionador dos problemas da instrução escolar. No cerne dessas discussões e, posterior a forte defesa da validação deste modelo de ensino, Justiniano de Mello, político, jornalista e professor, não poderia deixar de apresentar o seu posicionamento quanto às configurações da educação do seu tempo. Diante dessa situação, utilizou o jornal Sete de Março como meio para circular e defender a sua opinião.

Justiniano de Mello e Silva nasceu em 08 de Janeiro de 1853, em Divina Pastora, Sergipe e formou-se em Direito pela Faculdade de Direito do Recife. Em Sergipe, foi lente da cadeira de Inglês e História Universal e da Civilização no Atheneu Sergipense nos anos de 1871 e 1896 respectivamente. Mudou-se para o Paraná, local onde ocupou cadeiras no Instituto Paranaense e na Escola Normal, foi Inspetor e Diretor Geral da Instrução Pública, além de contribuir e redigir em alguns jornais.

$\mathrm{O}$ intelectual foi um indivíduo que participou intensamente de embates políticos e de *Endereço eletrônico: ss.barbarasilva @ gmail.com *** Endereço eletrônico: cristianoferronato@ gmail.com

****Endereço eletrônico: stos.anderson@ gmail questões sobre a educação na Província paranaense. Ele foi eleito Deputado Estadual em quatro legislaturas: em 1878, devido ao falecimento do deputado Lourenço Taborda Ribas de Andrade; em 1879, ano em que foi escolhido pelos conservadores; em 1882 e 1889, quando novamente foi eleito pelo mesmo partido; e em 1891 tomou posse do cargo de deputado pelo Partido Operário.

$\mathrm{Na}$ qualidade de membro do Partido Conservador, fundou e redigiu o jornal 25 de Março em 1876. Em 1877 publicou no $O$ Paranaense e, em 1882, na Gazeta Paranaense e Jornal do Commercio. Justiniano de Mello foi o redator do periódico Sete de Março fundado em 1888, pertencente ao partido conservador, onde neste fez veicular seus escritos a respeito de variados temas sobre a configuração do ensino da época. Contribuiu também para a Revista Azul (1893) e o Cenaculo (1895).

No ano de 1876, Justiniano de Mello fez parte do primeiro quadro de professores da Escola Normal, onde lecionou a cadeira de Pedagogia e a de Religião e Grammatica Philosofica da Lingua Portugueza do Instituto Paranaense. Nessas mesmas instituições, em 1884, assumiu o cargo de professor de Pedagogia theorica e prática, entre 18 de maio e 
$1^{\circ}$ de junho de 1888 substituiu o lente de Philosofia e história e, no ano de 1893, ocupou a cadeira de História Universal. Em 15 de Julho de 1896 foi aposentado de suas funções.

Durante as suas atuações na política e na educação do Paraná, Justiniano de Mello entrou para o meio jornalístico, fundando e redigindo periódicos ora de partidos políticos ora de seus amigos, os quais, por vezes, faziam parte de sua rede de difusão de ideias. Era a partir desses meios de comunicação que este literato propagava suas opiniões sobre o que estava posto na sociedade da época. Os seus pensamentos refletiram tanto sobre as questões políticas quanto sobre aspectos relacionados à educação, ao direito e à literatura.

\section{A "força theorica do methodo intuitivo"}

À medida que lemos os textos de Justiniano de Mello, percebemos temáticas comuns que caracterizam o método intuitivo. Conforme Valdemarin, este método

[...] pode ser sintetizado com dois termos observar e trabalhar [...]. Observar significa progredir da percepção para a idéia, do concreto para o abstrato, dos sentidos para a inteligência, dos dados para o julgamento. Trabalhar, implica a adoção de uma descoberta genial creditada à Froebel, que consiste em fazer do ensino e da educação na infância uma oportunidade para a realização de atividades concretas, similares àquelas da vida adulta. Aliando observação e trabalho numa mesma atividade, o método intuitivo pretende direcionar o desenvolvimento da criança de modo que a observação gere o raciocínio e o trabalho prepare para o futuro produtor, tornando indissociáveis pensar e construir" (VALDEMARIN, 1998, p. 69-70).

De acordo com a autora citada, o método intuitivo trazia em si "[...] a proposição de que a aprendizagem tem seu início nos sentidos, que operam sobre os dados do mundo para conhecê-lo e transformá-lo pelo trabalho e que a linguagem é a expressão deste conhecimento." (VALDEMARIN, 1998, p. 74-75). Para Justiniano de Mello, se os sentidos são as primeiras faculdades que se aprimoram em nós, a cultura destes torna-se o cuidado essencial para a educação.

Esta cultura não refere-se somente ao exercicio, ao uso dos órgãos, mas á correcção do juizo, ao vigor do caracter. Não basta ainda que estas aptidões sejam adquiridas; é de mister tambem referi-las, applica-las á pratica da justiça, ao goso do bello, á conquista da felicidade (SILVA, 1888a, p. 1).

Dito de outro modo, não é somente utilizar os órgãos que correspondem a um sentido, mas instruí-lo durante a infância para, no futuro, quando adulto, saber fazer bom uso dos mesmos. Justiniano de Mello demonstrou bem isso em seus textos intitulados Cultura dos sentidos, publicados nas edições 7, 8 e 9 do jornal Sete de Março. O professor sergipano iniciou destacando a distinção entre o homem selvagem e o civilizado a fim de demonstrar o desenvolvimento dos sentidos entre ambos:

O selvagem, sitiado pela natureza, põe em contribuição a sagacidade sensorial, que o distingue, e vence a tyrannia da necessidade: o homem civilizado apropria-se dos instrumentos que lhe proporcionam os progressos da sciencia e da industria, e penetra pouco a pouco, na região do incognoscivel. Um olha de preferencia para o exterior, porque a vida do espirito concentra-se na resistência contra os elementos de destruição que o obsediam: o outro, na observação mesma do mundo visivel, lança um olhar perscrutador para os mysterios da sua alma, e subordina as exigências physicas á parte espiritual do seu destino (SILVA, 1888a, p. 1-2).

As diferentes sensações dos dois tipos acima referidos baseiam-se nos sentidos próprios para cada sensação. Estes, por sua vez, podem ser instruídos para tornar as sensações mais vivas e nítidas, "[...] assim como diminuir-lhes, até certa medida, a intensidade. Esta educação facilita-se pelo auxilio reciproco que prestam as diversas sensações." (SILVA, 1888a, p. 2). Como mencionado, os sentidos possuem uma estreita relação com o método intuitivo, pois “" [...] permitem a comunicação com o mundo, produzindo sensações geradoras de percepções que, por sua vez, produzem concepções que são retidas pela memória. É sobre este material que operam o raciocínio e a imaginação, produzindo juízos." (VALDEMARIN, 1998, p. 77). Assim, com eles a criança passa a ter maior contato com objetos reais, explorando a sua intuição.

Perante essas questões e como meio para melhor elucidar a relevância dos sentidos no desenvolvimento humano, Justiniano de Mello explica como cada um deles pode ser educado. Do paladar, ele diz que esse sentido é pouco desenvolvido na infância, mas que pode chegar a 
um ponto prodigioso quando bem desenvolvido, ou seja, um adulto conhecedor de vinhos, por exemplo. Segundo o professor, na primeira infância, quando uma criança insiste em recusar um alimento significa, por vezes, que o sabor não a agradou e, desta forma, são dificilmente digeridos. Diante dessa situação, não "[...] devemos dar ás crianças tudo quanto ellas desejam comer", mas educar o seu organismo. Com isso,

Quando o menino revela aversão por toda uma serie de alimentos, não se combatera o mal, que deste estado dellue, empregando contra elle ameaças ou pancadas. A fome é neste caso melhor medico. Após um exercicio prolongado, após um passeio em que foi vencida regular distancia, o appetite violentamente atiçado, pode eliminar a repugnancia que enfadonhamente se impunha. Impôr aos estomagos, de tempos em tempos, algumas pequenas privações, é traçar um caminho que pode levar o menino á sobriedade, e apparelha-lo para privações maiores na idade adulta (SILVA, 1888a, p. 2).

Conforme a criança consome alimentos que não agrada o seu paladar no momento em que a fome está presente, há grandes chances de ela aprender, de maneira tranquila, a saborear o que antes não gostava. Um grande aliado para este sentido é o olfato, "[...] orgão universal de sentimento; [...] um olho que vê os objectos, não somente onde eles estão, mas por toda parte onde estiveram." (SILVA, 1888b, p. 1). Assim como o paladar, o olfato apresenta pouco desenvolvimento na infância e acompanha o homem até os seus últimos dias de vida. Comparando-se com a visão, audição e o tato, "[...] elle não subministra tantos elementos á inteligência [...]”, porém conduz à imaginação, "[...] talvez porque elle nos faz adivinhar a natureza e a propriedade de diversos corpos." (SILVA, 1888b, p. 2).

Para Justiniano de Mello, se o olfato parece um sentido auxiliar, é porque não foi dado o desenvolvimento necessário. Ele indica como isso pode ser realizado, destacando que:

As crianças podem ser exercitadas depois dos trez primeiros annos, na gamma dos cheiros. Um brinco, que não faltará de encanto e de deleite, facilitando ao mesmo tempo o conhecimento das qualidades odoriferas, será o de distinguir, a olhos fechados, os perfumes de differentes flores que serão approximadas das narinas do menino. Cada qual comporá um ramilhète com as flores que houver reconhecido, dando-se á criança, como premio, o que maior perfeição assignalar no sentido assim posto em actividade. Quando em adulto o individuo puder, por força dos exercicios infantis, pôr em contribuição o olfacto na classificação das plantas e dos mineraes, agradecerá, por certo, o cuidado particular que mereceu a sua educação physica (SILVA, 1888b, p. 2).

Podemos levar em consideração que pode ser feito isso na escola como meio de explorar o olfato infantil, aproximando as crianças às coisas concretas e, de certa maneira, estimulando a sua imaginação. Como citado por Justiniano de Mello, ao sentir o aroma de flores variadas o indivíduo, à medida que pratica essa atividade, futuramente conseguirá distinguir os tipos podendo, assim, classificá-las. Esse não é um exercício em vão, dado que este sentido auxilia alguns profissionais, como o "[...] chimico, ao botanico, ao pharmaceutico, ao industrial e ao commerciante." (SILVA, 1888b, p. 2).

Em coerência com os fundamentos do método intuitivo, o contato da criança com a natureza nos leva a pensar na curiosidade existente nela sobre a pluralidade dos objetos presentes no meio ambiente. Segundo Valdemarin, o estudo da natureza assumiu, com a introdução do método intuitivo, a condição de conteúdo escolar, passando, assim, a ser vista como "[...] a principal inovação curricular introduzida na educação pré-escolar [...] pelo fato de possibilitar o conhecimento da forma, da força e do movimento, elementos presentes em vários aspectos da vida, sejam eles concretos ou abstratos.”. A observação, nesse caso, “[...] é o atributo humano que proporciona a percepção e a compreensão das forças naturais, por meio da constatação das propriedades da matéria, [...] gerando assim um conhecimento, ainda que sumário, da própria organização humana." (VALDEMARIN, 2004, p. 108).

Justificando essa prática, um dos sentidos que auxilia tal exercício é a visão, a qual, consoante Justiniano de Mello, é incerta, confusa e incorreta nos primeiros dias de vida do ser humano. Para ele, se "[...] a criança não dá signal algum que ateste a presença dos phenomenos da visão, mais tarde os objectos serão distinguidos, e a sensibilidade não se affirmará somente ao aspecto de cores acentuadas e claridades vivas." (SILVA, 1888c, p. 2).

Conforme o mesmo autor, o uso abusivo e errôneo dos olhos durante a infância pode gerar distúrbios futuros na visão. Por isso,

Diz-se, e nós repetimos, que as enfermidades da 
vista são na máxima parte devidas á má, ou nenhuma educação que se lhe dá no periodo da infância. Podem, é certo, exercer consideravel infuencia sobre a propagação do mal, a debilidade crescente do organismo humano, e o abuso de certos exercícios que affectam particularmente esse orgão. Lembremo-nos, entretanto, de que são raros os maritimos que não possuam boa ou excelente vista. Ahi a applicação assídua do apparêlho da visão, augmenta a potencialidade deste, sem que de tal facto se possa inferir qualquer affinidade entra a perfeição do sentido e o gráo de robustez do organismo geral (SILVA, 1888c, p. 2).

Para evitar posteriores enfermidades, Justiniano de Mello defende que

[...] não devemos expòr a vista das crianças, durante o periodo da amamentação, aos raios offuscadores do sol, evitando que ellas voltem o rosto para o lado do firmamento. Alguns meninos adquirem o habito de esfregar os olhos com o punho fechado, o que é funesto. Aos trez annos de idade, o menino dispõe de pouca vista, mas esta pode descobrir os objectos mais exíguos, desde que os explore muito de perto. D'ahi o costume de approximar muito do olho tudo quanto quer examinar, produzindo-se deste modo uma tensão que exagera a curvatura da córnea e accumula uma grande força de refracção nos meios refringentes do apparêlho: este estado desde que se torna permanente, pode conduzir fatalmente á myopia (SILVA, 1888c, p. 2).

Assim, os cuidados com a visão, bem como a educação dela, necessita ser feita desde os primeiros dias de vida para conservar a integridade da vista. Como mecanismo para manter essa integridade, nos discursos higienistas estava presente "[...] o processo mais conveniente de iluminar as salas escolares." (SILVA, 1888c, p. 2). Valdemarin aponta que,

Para se obter um bom resultado na utilização do método intuitivo, o ambiente escolar deve ser claro e arejado, ornamentado com trabalhos feitos pelos próprios alunos e nas salas de aula deve haver um conjunto de material disponível para cada uma das crianças. Todas as atividades devem ser feitas gradualmente, dividindo-se a instrução em séries lógicas de exercícios, adotando-se as mesmas regras orientadoras para um conjunto de pequenos trabalhos, a fim de evidenciar a coerência dos procedimentos (VALDEMARIN, 1998, p. 74-75).
Tanto a iluminação, quanto os trabalhos expostos das crianças na sala de aula, serviam para educar a visão com a perspectiva de aguçar a curiosidade, conduzindo-as a quererem observar as belezas do mundo. Ao passo que voltamos nosso olhar para crianças, sabemos que elas não se contentam em apenas olhar para as coisas, mas almejam tocá-las, ou seja, carregam a necessidade de sentir aquilo que vislumbram. Nos primeiros anos de vida, o indivíduo tenta pegar objetos que estão fora do seu alcance e, no momento em que aqueles caem de suas mãos, é manifestado o que Justiniano de Mello chama de "a natureza de exercitar o sentido tacto". Conforme o autor, o menino, "[...] movendo-se em diversos sentidos, procura apanhar e reter todos os objectos que se lhe offerecem. As cousas, ainda as escapam á acção do homem, a lua, as estrellas, a bella nuvem que passa, cáem sob o domínio das pretenções da criança." (SILVA, 1888a, 2).

Valdemarin (1998, p. 77), utilizando-se dos aportes do manual de Norman Calkins, assinala que,

Em coerência com os princípios norteadores do método, as lições são organizadas tendo por critério a importância atribuída a cada um dos sentidos para a aquisição do conhecimento, iniciando-se pelos conteúdos mais adequados à percepção visual e finalizando com aqueles que têm no tato seu suporte cognitivo. A premissa, inquestionável para o autor, tanto da concepção de homem, quanto das proposições didáticas é que o conhecimento do mundo material é proveniente dos sentidos e expresso por meio das palavras, sendo a percepção a atividade mais simples da inteligência. Daí decorre a necessidade da criação de situações que se constituem na atividade por excelência da escola.

Perante essa conjuntura, convém "[...] apressar a educação sensorial da criança, de modo que esta venha cedo a conhecer a natureza dos corpos, os estados e propriedades das cousas." (SILVA, 1888a, p. 2). Quando, por exemplo, uma mãe aproxima o dedo do seu filho à luz de uma lâmpada, ela o ensina a evitar, pois futuramente pode ocorrer uma queimadura. Ademais, é fundamental habituarmos a criança a "andar nas trevas" a fim de poupá-las de circunstâncias difíceis às quais não poderão ser afastadas. Outra situação consiste na "[...] escuridão, e em circumstancias nas quaes a vista não possa ser aproveitada, o tacto 
augmenta de fineza, e substitue em parte o sentido que se immobilisa." (SILVA, 1888a, p. 2). À vista disso, a educação deve promover, segundo Justiniano de Mello, durante a primeira infância:

$1^{\text {o }}$ o embotamento da sensibilidade do tegumento externo (pelle), de modo a diminuir em grande parte a sensação do calor e do frio; $2^{\circ}$ a concentração na mão de uma sensibilidade exquisita, imprescindivel para a distincção das impressões tactis. A resistencia, a solidez, o tamanho, a figura dos corpos, são noções que por tal forma penetram em gora hora no espirito do menino. Alem dessa vantagem, devemos lembrar a superioridade adquirida pelo individuo que cultivou o apparèlho prehensor: em todas as posições, o homem colherá os beneficios desta educação (SILVA, 1888a, p. 2).

Ou seja, tem de aproximar o menino a diferentes texturas, estimulando a observação e propiciando o conhecimento do mundo através de sensações. Logo, estendendo o número de "[...] objectos, sobre os quaes se exercerá a acção do menino, escolhendo-se aquelles que mais afiam a curiosidade, sem cançar a attenção, corrigem-se falsas impressões, e dirige-se o sentido de modo a ser cêdo e justamente utilisado." (SILVA, 1888c, p. 2, grifo do autor). Pode chamar-se também de "sentido da amizade". Para Justiniano de Mello, "[...] o ouvido é o educador da voz: esta, deve-lhe o accento, o rythmo e a paixão." (SILVA, 1888b, p. 2).

Nas crianças, logo após o nascimento, a audição é limitada, pois ainda não recebeu todo o seu desenvolvimento. Ao longo do tempo, o órgão deste sentido sofre alterações decorrentes da sensibilidade às ondas sonoras, sejam elas fracas ou mais intensas, vai depender da condição em que o indivíduo se encontra, pois, o "[...] ouvido é susceptivel de aperfeiçoar-se pela educação", sendo que uma "[...] audição rica é um thesouro inestimavel, mas também não é o lote de todos os homens, e as mais das vezes denuncia esforções nutridos e perseverantes, cuidados particulares consagrados á educação do sentido." (SILVA, 1888 b, p. 2, grifo do autor).

Educação esta que pode ser realizada a partir das canções das mães para os filhos se acalmarem e dormirem. Como detalha Justiniano de Mello,

Temos visto maravilhas da voz na educação dos meninos. Uma aria, por vezes destituida de senso, mas cantada pela voz materna junto ao berço da criança, afugenta a irritação ou combate maravilhosamente os symthomas de uma crise nervosa. Crianças indóceis, inquietas, irritadiças, depois de burlarem tudo quanto se envida para chama-las ao somno, adormecem como por encanto aos sons de uma cantiga monótona entoada pela meiguice das mães (SILVA, 1888b, p. 2).

Cantar músicas também poderia ser feito nas escolas a fim de controlar as crianças. Além disso, utilizar os sons das palavras, aliada a visão, para o ensino da escrita é um meio de levar a criança a observar e a se interessar por aquilo que escuta e fala com intenções para a aprendizagem da linguagem. Isto, de certa forma, relaciona-se ao estudo da gramática, este que, para o autor citado, seria satisfatório se não fosse "[...] somente um exercicio constante de estylo, como tambem um esforço para communicar aos pensamentos essa originalidade typica, que o habito de copiar e repetir os conceitos alheios acaba por obliterar.". É a maneira de o menino comunicar o seu pensamento através da palavra, em traduzir "[...] os seus sentimentos, de viva voz ou por escripto." (SILVA, 1890a, p. 2).

Resta então adaptar as diretrizes gerais do método intuitivo à aprendizagem da leitura e da escrita, abordando os aspectos referentes ao pensamento e à linguagem, sua encarnação. [...], o pensamento e a linguagem são também fatos observáveis já que, adquirir consciência das próprias operações intelectuais, processo ao qual denominam como reflexão, consiste justamente numa observação do próprio pensamento. Além disso, o pensamento adquire uma forma por meio das palavras, que são compreendidas pela junção de sons, "envelopes das idéias", e que são também elementos diretamente observáveis (VALDEMARIN, 2004, p. 109).

$\mathrm{O}$ método intuitivo visava à aprendizagem da leitura através da manifestação do pensamento em linguagem, seja ela falada ou escrita, a qual é consequência da reflexão do que foi observado. Porém, a ortografia torna-se, conforme Justiniano de Mello, um martírio por conta das suas regras. Ele critica o estudo da gramática por considerá-lo "enfadonho" e que para evitar tal situação, é necessário fazer exercícios onde o professor possa fiscalizar, "sem tormento", "[...] o emprego das palavras, cujo sentido deve ser sempre comprehendido com exactidão". Como ele dispõe:

Os exercícios de composição começarão bem 
pela descripção dos objectos conhecidos e familiares. Desde que for fielmente indicada a forma, a substancia de que foi feito, convem inciar os meninos nas diversas applicações de que este é susceptivel. Mais tarde, as licções versarão sobre factos mais complexos: uma arte, um officio mechanico, um acontecimento, um quadro, poderão ser submettidos a apreciação da criança. Tendo-se sempre em vista a utilidade derivada do assumpto proposto (SILVA, 1890a, p.2).

Partir de palavras conhecidas para a aprendizagem de novas é demonstrar os usos reais da linguagem a fim de conduzir o aluno ao gosto pela leitura mediante a observação, onde ele "[...] transporá por si mesmo as barreiras oppostas ao aprendizado da lingua materna [...]". Por isso, devemos ter cuidado em "[...] emiitir, juntos as crianças, sons justos, entonações sonoras, articulações correctas, dirigindo-se por tal forma o espirito imitativo que tão promptamente desperta na infância." (SILVA, 1890a, p.2). Para Justiniano de Mello, a imitação é o primeiro educador da criança e o gérmen do progresso da imaginação, onde o indivíduo menor consegue construir os preceitos morais a partir da atividade imitativa.

Neste aspecto,

[...] Os exercícios de reprodução exata e de cópia são justificados em sua imbricação com a educação moral, afirmando-se ser desejável que a criança aprenda a submeter um pouco de sua fantasia a uma lei superior, uma necessidade lógica. [...] Do ponto de vista didático seria um erro desastroso proibir a expressão livre e espontânea do pensamento infantil mas, não se submeter ao pensamento de outro é criar uma ilusão desnecessária. Sobrepõe-se, neste caso, um argumento utilitário: na vida, nem tudo é inventado; grande parte das realizações humanas consistem em imitação, tradução e cópia e em todas as profissões e artes a cópia é um dos componentes. Assim como o adulto, a criança deve copiar, partindo do que já existe e é bom que aprenda a fazê-lo. Enquanto demonstração e aprendizagem de procedimentos, a cópia ou a reprodução exata de uma forma é atividade educativa que se impõe, portanto, como uma necessidade social (VALDEMARIN, 1998, p. 73).

A aprendizagem por meio da imitação não significa que a criança reproduzirá o que é feito pelo adulto. Com base no que é visto, ela desenvolve um modo de pensar semelhante ao que é direta ou indiretamente ensinado. Então, podemos fazer algo para "[...] fomentar a produção do caracter, e impedir que este se torne como uma flor rara numa floresta de arbustos vulgares?". Conforme Justiniano de Mello, nessa etapa da vida, quase nada. $\mathrm{O}$ adulto não consegue interferir a vontade do menino, pois o caráter está em constantes mudanças e aplicar castigos não impedirá " [...] o temor de fazer o mal." (SILVA, 1890b, p. 2).

De acordo com mesmo autor,

O menino não fabrica os deuses que deve adorar. Do exterior, è que elle recebe as impressões que o educam, que intellectualmente o desenvolvem que o levam até o portico do templo da sciencia. Os clarões da consciencia, são na alma infantil como traços radiantes da phisonomia paterna. Os dous polos da vida moral, a felicidade e a desgraça, apparecem-lhe ora na severidade rispida e sombria do seu progenitor, ora, nas puras e suaves caricias da ternura maternal (SILVA, 1890b, p. 2).

Não limitar as crianças para elas tornaremse quem são é o meio para conduzi-las a livre formação do caráter, visto que a "[...] inspiração do sentimento, que forma o caracter, como o vôo da imaginação realisa as obras eminentes da poesia e da esculptura, demanda liberdade de acção, espaço e perspectivas attrahentes." (SILVA, 1890b, p. 2). Essa independência suscita a aproximação e experimentação de objetos e situações da vida real, podendo ser concebido, assim, o conhecimento. Diante destas considerações, notamos que a intenção metodológica do ensino intuitivo com base nos sentidos era a de:

[...] educar a criança a partir de novos padrões intelectuais, que têm sua origem numa nova concepção sobre o conhecimento, que postula a origem das idéias nos sentidos humanos e que, aplicada ao ensino, pretende formar indivíduos que usem menos a memória e mais a razão e que valorizem a observação e o julgamento próprios como meios de construção do conhecimento e da implementação das atividades produtivas. (VALDEMARIN, 1998, p. 80).

A observação e a experimentação de novas situações, respaldadas no vivenciado e a intuição infantil concedem as crianças à possibilidade de aprender e criar simultaneamente, além de despertar a curiosidade e a vontade em adquirir conhecimento. Por meio dos sentidos, um imenso cabedal de saberes é obtido "[...] aonde estes não 
attingem, suppre a entelligencia, inferindo o conhecimento do desconhecido, passando dos objectos sensiveis aos que não o são, abstrahindo e generalisando." (SILVA, 1890c, p. 1). É com as "atividades produtivas" que ocorre a transição entre as ideias concretas e as abstratas que, para Justiniano de Mello, são uma guisa de a criança ter conhecimento sobre as coisas.

Para ele, a ideia abstrata é "a mãe das artes e das sciencias", pois o homem estaria incapacitado de progresso "se não lhe fosse dado remontar da ideia concreta a ideia abstracta, e desta ás leis geraes que regem o universo." (SILVA, 1890d, p. 2). Já as concretas, referem-se à representação das coisas que são observadas "[...] e não separa da substancia os attributos, ou a propriedade do ser [...]" (SILVA, 1890c, p. 1). Quando a criança chegar ao ponto de conseguir distinguir essas ideias, é necessário exercitar esse feito questionando sobre a natureza e propriedade dos seres.

Perguntas dirigidas ao menino sobre o que seja a côr, a sonoridade, a densidade etc., força-lo-hão a pensar, e por consequencia a achar por si mesma solução para um grande numero de questões. Em vez de empregar a cifra abstracta no estudo da arithmetica, seria preferivel representar objectos por modo visivel. A grammatica prepara a intelligencia infantil para concepções mais altas; mas seria desastrado o systema que se propuzesse accumular regras e exemplos, sem attenção ao gráo de sagacidade do alumno (SILVA, 1890d, p. 2).

Para se conhecer as coisas como elas são e as suas relações, é preciso que a reunião de ideias abstratas torne-se uma, sendo que, ao perderem a individualidade, transformam-se em um conjunto de coisas comuns ou gerais. Como exemplificado por Justiniano de Mello:

Côr, sabor, cheiro, dureza, solidez, belleza, attracção, eles são ideias abstractas. Observando os modos da couza, de cada um delles formamos uma ideia distincta, que referimos pela generalisação a um conjunto de seres. Sabedoria, virtude, dignidade, grandeza, guerra, navegação, tambem são productos dessa grande faculdade, que possuímos, de abstrahir, substantivando actos para crear ideias communs à uma serie de objectos (SILVA, 1890d, p. 1-2).

É a construção daquilo que não é concreto para o que é. O menino não reconhece o objeto quando $\mathrm{o}$ entregamos pela primeira vez.
Fundamentando-se em suas novas experiências e nas que já vivenciou, ele é conduzido a ter um entendimento preciso sobre o apresentado. "A principio, o menino verá uma arvore, isto é, aquella que habitualmente lhe mostram; mais tarde uma floresta será simplesmente arvores, isto é, uma collecção de objectos da mesma figura." (SILVA, 1890c, p. 2).

Justiniano de Mello aponta que é mais fácil o indivíduo adquirir as ideias concretas durante a infância, do que quando adulto. Isto ocorre em razão de a flexibilidade cerebral da criança ser mais sensível, pois nesta faixa etária, nós adquirimos com mais agilidade os novos conhecimentos. "As plantas, os mineraes, os insectos, com os seus nomes e figuras, constituem provisões intellectuaes de rapida acquisição para a infancia. Mais tarde, [...] esses conhecimentos são dificilmente obtidos pelo homem." (SILVA, 1890c, p. 1).

Neste momento de aprendizagem, a curiosidade pode ser aguçada, sendo ensinadas coisas as quais serão úteis para a vida cotidiana.

Elle tomara um bocado de argila, lhes dirá a respectiva composição chymica, quaes são as qualidades dela. Mostrar-lhes-ha como essa terra, amollecida pela agua, toma sob a roda do oleiro as formas mais variadas, como ella secca sem fendas, como adquire pela cozedura, a dureza da pedra. Depois virà a applicação do esmalte a composição deste, enfim os mil detalhes de semelhante fabricação (SILVA, 1890c, p. 2).

Deste modo, a criança, a partir de sua curiosidade quanto aos detalhes das coisas que são apresentadas, entenderá o funcionamento e aplicabilidade das mesmas em sua rotina. Elas discernem, "[...] por instincto, um sem numero de qualidades, nas cousas que incidem sob a sua observação jornalera.". Assim, é profícuo que “[...] o menino adquira, logo que a intelligencia se manifeste, o conhecimento do maior numero de objectos possivel. Emquanto não for bastante vasto o circulo das ideias, o estudo dos atributos e propriedades pode ser omittido sem inconveniente." (SILVA, 1890c, p. 2).

Quando ocorre a mudança da ideia particular para a geral, é necessário motivar a atenção da criança quanto às diferenças e igualdades da propriedade e atributos de cada objeto. "O criterio das distincções não se obterá sem trabalho; mas uma vez encaminhado nesta direcção o entendimento infantil, a curiosidade natural farà o 
resto.". Com isso, ao conhecer uma árvore, convém ser apresentado a criança distintos tipos de árvores e características comuns entre elas para se obter uma classificação. Assim, ela compreenderá as divisões, as subdivisões e as relações desta categoria. "Uma casuarina, uma laranjeira, uma nogueira, não serão mais confundidas com as outras arvores, embora offerecendo um aspecto geral semelhante." (SILVA, 1890c, p. 2).

Este método de aprendizagem a partir das coisas, o intuitivo, influenciou, no final do século XIX,

[...] várias proposições pedagógicas, devidamente resguardadas em sua singularidade, que buscaram na escola o meio de desenvolver os sentidos, de selecionar experiências pedagógicas que privilegiem as coisas ao invés das palavras, de materializar o conhecimento em objetos, de propor atividades de ensino concretas e mensuráveis e acima de tudo, produzir idéias claras e distintas (VALDEMARIN, 1998, p. 80).

À vista disso, com a adoção deste método, a escola pretendia tornar o aluno participante da sua aprendizagem, sendo contrário ao modelo de ensino mecânico e repetitivo. Em conformidade com o ensino intuitivo, a educação da qual Justiniano de Mello discutiu em seus textos é aquela baseada nos sentidos. Nela, a criança tem o contato com a natureza através dos sentidos. Com eles, ela poderá ver, tocar, sentir, provar, ouvir e, apoiada nas circunstâncias vivenciadas e na imaginação, discorrerá sobre a experiência, gerando, assim, o conhecimento e, consequentemente, a formação do caráter a partir do que foi vivido.

\section{Considerações finais}

O interesse de Justiniano de Mello em discutir temas da educação nos jornais era característica dos homens do seu tempo. Eles tinham em si objetivos de informar e instruir aqueles que os liam. Com seus projetos de reformas da organização educacional, os sujeitos que eram educadores, jornalistas, políticos, diretores e proprietários de escolas consideravam que, por intermédio da educação, eles conseguiriam modificar o cenário da nação. De certa forma, eles foram, no Brasil, os responsáveis pela veiculação da ideia do método intuitivo. (SCHELBAUER, 2005).

Como professor da Escola Normal, o empenho de Justiniano de Mello em escrever sobre o método intuitivo pode ter sido um meio de esclarecer aos seus alunos o que o mesmo era. Do lado jornalístico, sua intensão era a de comunicar aos seus leitores. Como "pedagogo nato", defender aquilo que seria melhor para a instrução revelou o seu ideário educacional com base em suas preocupações quanto ao que estava posto.

Para o professor, a adoção desse método ocasionaria o avanço da sabedoria do aluno dentro e fora do âmbito escolar. $\mathrm{O}$ método intuitivo contemplava o ideário educacional de Justiniano de Mello. Observação, curiosidade, imaginação, a criança em contato direto com as coisas do mundo. Com essas circunstâncias, ela poderia tornar-se uma inventora, bem como estruturar o seu caráter, tendo a imitação como uma grande aliada. O ensino, deste modo, não abrangia atividades passivas longas e de deduções sem fundamentos. Com as atividades que excitavam a imaginação, o mestre conduziria os seus alunos a resultados extraordinários $\mathrm{e}$ imprevistos. Essa era, para o intelectual, a força teórica do método intuitivo.

\section{Referências}

SCHELBAUER, Analete Regina. O método intuitivo e lições de coisas no Brasil do século XIX. In: STEPHANOU, Maria; BASTOS, Maria Helena C. História e memórias da Educação no Brasil. Vol. II - Século XIX. Petrópolis: Vozes, 2 ed., 2005, p. 132-149.

SILVA, Justiniano de Mello e. Cultura dos sentidos: a) O tacto, b) O paladar. Sete de Março, Paraná, n. 7, 6 jun. p.1-2, 1888a. Disponível em: <http://bndigital.bn.gov.br/hemeroteca-digital/> Acesso em: 06 out. 2016.

SILVA, Justiniano de Mello e. Cultura dos sentidos: c) O olfacto, d) O ouvido. Sete de Março, Paraná, n. 8, 13 jun. p.1-2, 1888b. Disponível em: <http://bndigital.bn.gov.br/hemeroteca-digital/> Acesso em: 06 out. 2016.

SILVA, Justiniano de Mello e. Cultura dos sentidos: e) A vista. Sete de Março, Paraná, n. 9, 20 jun. p.12, 1888c. Disponível em:

<http://bndigital.bn.gov.br/hemeroteca-digital/> Acesso em: 06 out. 2016.

SILVA, Justiniano de Mello e. Didática da língua 
materna. Sete de Março, Paraná, n. 94, 8 fev. p.2-

2,1890a. Disponível em:

<http://bndigital.bn.gov.br/hemeroteca-digital/>

Acesso em: 13 out. 2016.

SILVA, Justiniano de Mello e. A moral e a infância II. Sete de Março, Paraná, n. 100, 22 mar. p.1-2, 1890b. Disponível em:

<http://bndigital.bn.gov.br/hemeroteca-digital/>

Acesso em: 14 out. 2016.

SILVA, Justiniano de Mello e. Ideias concretas.

Sete de Março, Paraná, n. 111, 14 jun. p. 1-2, 1890c.

Disponível em:

<http://bndigital.bn.gov.br/hemeroteca-digital/>

Acesso em: 15 out. 2016.

SILVA, Justiniano de Mello e. Ideias abstratas. Sete de Março, Paraná, n. 112, 21 jun. p. 1-2, 1890d.

Disponível em:

<http://bndigital.bn.gov.br/hemeroteca-digital/>

Acesso em: 15 out. 2016.

VALDEMARIN, Vera Teresa. Método Intuitivo: os sentidos como janelas e portas que se abrem para um mundo interpretado. In: SOUZA, Rosa Fátima de; VALDEMARIN, Vera Teresa; ALMEIDA, Jane Soares de. O legado educacional do século XIX. Araraquara: UNESP - Faculdade de Ciências e Letras, 1998, p. 63-106.

VALDEMARIN, Vera Teresa. Estudando as lições de coisas: análise dos fundamentos filosóficos do método intuitivo. 1 ed. Campinas, SP: Autores Associados, 2004.

\section{Sobre os autores}

Bárbara da Silva Santos: Doutoranda em Educação do Programa de Pós-Graduação em Educação da Pontifícia Universidade Católica do Paraná (PUCPR); Mestre em Educação pelo Programa de Pós Graduação em Educação da Universidade Tiradentes (PPED/UNIT, 2017); Licenciada em Pedagogia pela Universidade Federal de Sergipe (UFS, 2014); Membro do Grupo de Pesquisa de História da Educação no Nordeste (GPHEN). Pesquisadora em História da Educação, com ênfase em Intelectuais e Imprensa.

Cristiano de Jesus Ferronato: Doutor em Educação com ênfase em História da Educação pela Universidade Federal da Paraíba (2012), Mestre em Educação pela Universidade Federal da Paraíba (2006) e Graduado em História pela Universidade Estadual de Maringá (2003). Professor PPG PLII e Coordenador do Programa de Pós-Graduação em Educação da Universidade Tiradentes - UNIT - em Aracaju, Sergipe, na linha de Educação e Formação Docente. Pesquisador do Instituto de Tecnologia e Pesquisa-ITP. Pesquisador associado ao Grupo de Pesquisa História da Educação no Nordeste Oitocentista (GHENO-PB), HISTEDBR (GT-PB) e líder do Grupo de Pesquisa História da Educação no Nordeste (GPHEN). Desenvolve pesquisas no campo da História da Educação, com foco especial sobre a instrução no oitocentos brasileiro.

Anderson Santos: Doutorando em Educação pelo Programa de Pós-Graduação em Educação da Pontifícia Universidade Católica do Paraná - PUCPR. Mestre em Educação com ênfase em História da Educação pela Universidade Tiradentes - UNIT (2016). Graduado em História pela Universidade Tiradentes - UNIT (2013). Membro dos grupos de pesquisa Instituições Escolares no Brasil (GPIEB) e de História da Educação no Nordeste (GPHEN). Desenvolve pesquisas no campo da História da Educação, com foco especial sobre a História dos Manuais Escolares e das Disciplinas Escolares.

Submetido em agosto de 2017.

Aprovado em janeiro de 2018. 